\title{
Do Consumers go by the Cover? A Survey of Selected Bakeries in Kolhapur
}

\author{
Dr. Vishakha Apte' ${ }^{1}$ Mr. Monish A. Motwani ${ }^{2}$ \\ ${ }^{1}$ Professor MBA, ${ }^{2}$ MBA II \\ 1,2Chhatrapati Shahu Institute of Business Education and Research, Kolhapur, Maharashtra, India
}

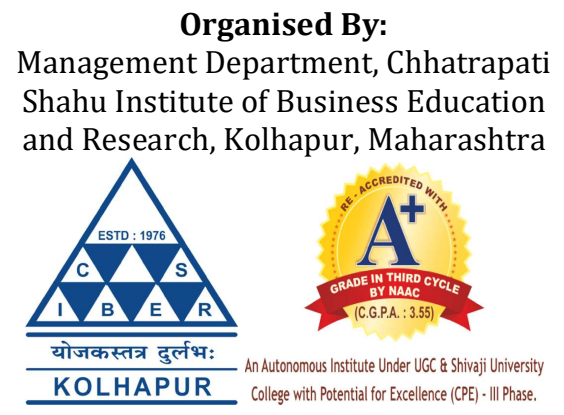

How to cite this paper: Dr. Vishakha Apte | Mr. Monish A. Motwani "Do Consumers Go by the Cover? A Survey of Selected Bakeries in Kolhapur" Published in International Journal of Trend in Scientific Research and Development (ijtsrd), ISSN: 2456-6470, Special Issue | Fostering Innovation, Integration and Inclusion Through Interdisciplinary

Practices in

Management,

March 2019,

pp.110-112, URL:

https://www.ijtsrd

.com/papers/ijtsrd

23077.pdf

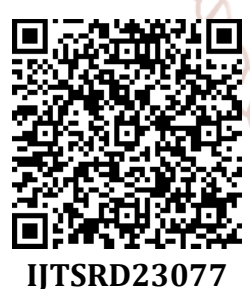

ABSTRACT

"Packaging can be theater, it can create a story." Said once Steve Jobs, legend in the concept of innovative and interactive design. The master who understood the pulse of the modern markets and created a history. Packaging is the first introduction of the product to the consumer. Packaging is also the first identity of the product. Packaging serves multiple purposes for the producer and also for the consumers. It is an important part of the middlemen's handling comfort and transporters' essential safety measure. In the competitive environment it is a tool of marketing in general and advertising in particular.

A study conducted in selected bakeries of Kolhapur for understanding the Role of Packaging in determining, Consumer Buying Behavior of food products is presented in this paper. It is a general observation that the packaging for the products of frequent purchase are not given due importance by the manufacturer such as the products sold in the bakery. The general perception is that, consumers buy such products on daily basis and hence they are not likely to notice its packaging. The objective of this paper is to find out the effect of the packaging on consumers buying decisions in case of food products sold in bakeries. Is Packaging a factor affecting consumers choice of the food products sold in bakeries? Consumers' purchase decision is a hardly a spontaneous action, there is a series of psychological and behavioral elements affecting it, also the marketing and informational tactics are in the play. The final opportunity to influence consumer's choice is through packaging. This important aspect is addressed in the paper.

KEYWORDS: Packaging, Consumers behavior, food products, bakery products, Wrapper Design, Plastic bags

\section{INTRODUCTION}

Packaging is an important aspect for both consumers as well as producers. The retailers also pay attention to the packaging officered by the producers whose products they sell in their stores. The producers are using it more as a marketing communication tool along with the basic element of their offering to the consumer. Packaging is the first experience of the product to the consumer. Packaging is also the first identity of the product. Even before consumers touch the actual product they touch the packaging. It is also the final opportunity to influence consumer's choice. How far the consumers of bakery products are paying attention to the packaging is the main focus of this study.

Packaging serves multiple purposes for the producer and also for the consumers. It is an important part of the middlemen's handling comfort and transporters' essential safety measure. In the competitive environment it is a tool of marketing in general and advertising in particular.

The data for the paper is sourced from a survey conducted in selected bakeries of Kolhapur for understanding the Role of Packaging in determining, consumer buying behavior of food products. It is a general observation that the packaging of the products of frequent purchase such as the products sold in the bakery are not given due importance by the manufacturer. The general perception is that, consumers buy such products on daily basis and hence they are not likely to notice its packaging. The objective of this paper is to find out the effect of the packaging on consumers buying decisions in case of food products sold in bakeries. Is Packaging a factor affecting consumers choice of the food products sold in bakeries? Consumers' purchase decision is a hardly a spontaneous action, there is a series of psychological and 
behavioral elements affecting it, also the marketing and informational tactics are in the play. Does packaging serve some other needs of the consumers apart from merely being a covering on the product or a marketing tool?

Statement of problem:

Role of packaging has not been given due importance by the manufacturers of food products in understanding consumers' buying behavior. This led to the study seeking role of packaging on consumer buying behavior using Kolhapur as a study area.

\section{Objectives of the study:}

1. To study the role of packaging with reference to consumer buying behavior.

2. To study the impact of packaging elements on consumers' purchasing decision.

3. To identify the elements to be highlighted while designing the packaging of a product.

\section{Review of some recent researches:}

Some studies and research papers published on the same topic during last five to six years were reviewed. Paper of MitulDeliya and BhaveshParmar (2012) titled, 'Role of Packaging in consumer buying behavior-Patan District' conclude that all the elements of packaging play import role in catching consumers' attention and interest. Empirical testing showed that visual elements like size and material of Packaging play an important role in consumers' decision making. Researchers in Peshawar in Pakistan (2013) reveal that, product attractiveness has significant effects on consumer's interest in the product. Consumers' differentiate and evaluate the product on the basis of the packaging. ( Sabeehullah Shah, Anand Ahmad, Nawaz Ahmad). The paper authored by JusufZekiri and VjollcaVisokaHasani in 2015 conclude from the empirical evidence that, 'information on packaging represents an important component and it can support marketing communications strategies of companies, and helps to create brand image and identity. It is helpful to consumers for making a studied decision. The important conclusion of this paper is about the language used on the package is an important factor influencing consumer buying decision. Further the paper states that, Innovation in package design also increase the value of the product in consumers mind. The paper of Clifford ZirraTizheOaya, Oputa Newman and ObumnekeEzie (2017) conclude that, 'visual appeal is more important than qualitative aspect of packaging, They found significant association between packaging color, background image, wrapper design and innovation in packaging where as no significant association between quality of packing material, information printed on packaging and consumers buying decision. In short the previous researches have shown that there is a significant effect of packaging on consumers buying behavior. This paper will particularly study the consumer behavior with respect to the packaging of bakery products including the daily purchase and frequently bought eatable sold in the bakeries.

\section{Research Methodology:}

Data collection: Primary data was collected from five major bakeries in Kolhapur namely. Madhuri Bakery, Bharat Bakery, Hindustan bakery, Khemraj Bakery and Chakote Bakery. On an average twenty buyers/respondents were selected randomly from each bakery. The selected respondents were asked to answer the questions given in the structured questionnaire. The data was collected for 100 respondents. The questionnaire containing fourteen questions related to the elements of packaging was distributed to the consumers making purchases in the above bakeries at different locations. The consumer responses like 'Yes' No and Cannot say, were converted into positive, negative and neutral response. The data collected was analyzed with the help of excel and the results were interpreted for examining them in the light of the objectives. The research papers reviewed for the study have repeatedly shown certain elements of packaging mentioned below. The same were included in the questionnaire. They include,

\section{Packaging Elements considered in the study:}

1. Packaging color:

2. Packaging Material:

3. Wrapper design:

4. Printed Information:

5. Background-image:

6. Innovation:

\section{Data Analysis and findings:}

\begin{tabular}{|c|c|c|c|c|}
\hline \multirow{2}{*}{$\begin{array}{l}\text { Sr. } \\
\text { No. }\end{array}$} & \multirow{2}{*}{ Question Asked } & \multicolumn{3}{|c|}{ Responses } \\
\hline & & Positive & Negative & Neutral \\
\hline 1 & Do you notice the packaging of the products that you buy from this bakery? & 80 & 13 & 07 \\
\hline 2 & Do you find packaging of the products in this bakery catching your attention? & 69 & 16 & 15 \\
\hline 3 & Does the color of packaging matter to you while selecting the product? & 52 & 35 & 13 \\
\hline 4 & $\begin{array}{l}\text { Do you prefer purchasing the products which have attractive background on } \\
\text { their packaging? }\end{array}$ & 28 & 60 & 12 \\
\hline 5 & Do you feel the quality of the packaging can protect the product? & 80 & 06 & 14 \\
\hline 6 & Do you feel that products packed in high quality material are safer than others? & 64 & 09 & 27 \\
\hline 7 & Does packaging help you to select products matching with your lifestyle? & 49 & 27 & 24 \\
\hline 8 & Do you feel that wrapper design is important in packaging? & 63 & 15 & 22 \\
\hline 9 & Do you read printed information on package of product? & 49 & 38 & 13 \\
\hline 10 & Do you evaluate the product according to the printed information while buying? & 29 & 59 & 12 \\
\hline 11 & Do you prefer packaging with better handling and transportation convenience? & 62 & 09 & 29 \\
\hline 12 & Do you notice any Innovation in packaging while buying the product? & 69 & 20 & 11 \\
\hline 13 & $\begin{array}{l}\text { Will innovation in packaging change your decision while purchasing the } \\
\text { product? }\end{array}$ & 58 & 20 & 22 \\
\hline
\end{tabular}


The above information is throwing light on the consumers' behavior in relation to the packaging of the products sold in bakery. The findings drawn from the above reveal the role of packaging, impact of packaging elements and it also gives clue to the producer about the elements to be highlighted while deciding about the packaging.

1. Quality of material used for packaging is of high importance to the consumers as $80 \%$ have given positive response.

2. As per the mandatory requirements of the foods and drugs authorities the information is printed on the packaging along with some advertising message from the producer/seller. But majority of consumers do not give importance to it or evaluate the product by reading the details on the package.

3. Consumers do notice the difference in packaging of different products; hence brand differentiation or product differentiation can be effectively achieved at the point of purchase, through innovations in design and coloring of the package.

4. Packaging with better handling and transportation are preferred by consumers. The consumers have to carry the product to their home or pace of consumption or open before use and then again store it in a different container also they have to dispose off the packaging material after the use so their convenience in all these issues is an important thing to be considered in packaging.

5. Consumers of bakery products give importance to the, 'Wrapper design', but it is not much.

6. Consumers may generally select those products whose packaging would reflect their lifestyle but in case of bakery products it is not prominently observed.

7. Consumers prefer the products which are packed in high quality material; also they feel that high quality material can protect the product.

8. Packaging information and attractive backgrounds have a little low importance compared to other elements.

9. Even though consumers buy bakery products very frequently they subconsciously notice packaging of different products and most of the packaging catch consumers' attention.

\section{Conclusions:}

The product may be an item of daily consumption; it may belong to a low price rage, it may be made locally, it may not be new but still its packaging matters. Bakery products are bought as per the taste of the consumers but in spite of that the consumers give importance to its packaging. From the producers point of view, it can be treated as one of the most important tool for communications, for making an impact on consumes' purchase decision. Packaging elements like packaging color, packaging material, innovation, wrapper design have a good impact on consumers. Whereas, printed information, background image comparatively have lesser impact on consumers. However, while designing a product a good combination of all elements will make the product more eye-catching and attractive. Packaging being able to communicate with consumers' easily, it has a increasing important role as a tool to attract consumers' attention and their perception on product quality. Even a good quality product needs good packaging so that consumers consider buying it even before actually experiencing it.

\section{References:}

[1] Clifford ZirraTizhe Oaya, Oputa Newman, Obumneke Ezie,2017, ' Impact of Packaging on consumer Buying Behavior in Nasarawa State' , International Journal of science: Basic and applied Research.(IJSBAR) ISSN 2307-4531

[2] Bidut Ghosh,2016, 'Impact of Packaging on consumers' Buying Behavior: A case study of Mother Dairy: Kolkata, 'Parikalpana-KIIT Journal of Management Vol 12(I) Jan-June 2016.

[3] Sabeehullah Shah, Anand Ahemad, Nawaz Ahmad, 2013, 'Role of Packaging in Consumer Buying BehaviorA Study of University Students of Peshawar Region KPK Pakistan, 'International Review of Basic and Applied Science July 2013 Vol. I Issue 2.

[4] Jusuf ZEKIRI, Vjollca Visoka HASANI,2015, ' The role and impact of the packaging effect on consumer buying behavior, 'ECOFORUM'Volume 4, Special Issue 1, 2015.

[5] Mitul Deliya, Bhavesh Kumar Parmar, 2012, ' Role of Packaging on Consumer Buying Behaviour - Patan District.,' Global Journal of Management and Business Research Vol12 Innsue 10 Version 1.0 June 2012. ISSN: 22494588 .

[6] Kotler Philip and Gary Armstrong,' Principles of Marketing'. 2017. Pearson.

Copyright (C) 2019 by author(s) and International Journal of Trend in

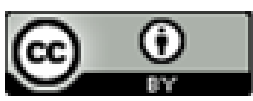
Scientific Research and Development Journal. This is an Open Access article distributed under the terms of the Creative Commons Attribution License (CC BY 4.0) (http://creativecommons.org/licenses/by/4.0) 